\title{
Self-knowledge, Discriminability, and Demonstrative Thoughts
}

\author{
Huiyuhl Yi*
}

Received: 18 March 2019 / Accepted: 30 August 2019

Abstract: According to content externalism, the content of our thought is partly determined by the linguistic environment responsible for it. However, there is growing skepticism about the compatibility of content externalism and self-knowledge. The skeptical position holds that, if content externalism is true, then we cannot know our own thought content because we would not be able to discriminate it from relevant alternative thought contents. This argument rests on the proposition that knowledge requires some type of discriminability. In this paper, I argue that this requirement does not apply to a particular type of demonstrative thoughts, more specifically, that in a typical case where we demonstratively denote an object without taking it as anything in particular, our secondorder judgment about our own thinking, whose content includes this use of a demonstrative, constitutes knowledge without due discriminability.

Keywords: Content externalism; demonstrative thought; discriminability; indefinite use of demonstratives; self-knowledge.

* Ulsan National Institute of Science and Technology

Division of General Studies, Ulsan National Institute of Science and Technology, 50 Unist-Gil, Ulju-gun, Ulsan, Republic of Korea

$\triangle$ huiyuhl@unist.ac.kr

(c) The Author. Journal compilation (C) The Editorial Board, Organon F.

This article is distributed under the terms of the Creative Commons Attribution-NonCommercial 4.0 International Public License (CC BY-NC 4.0). 


\section{Introduction}

Content externalism claims that the content of our thought is determined in part by our external environments. The classic argument for content externalism is inspired by Hilary Putnam (1975)'s famous Twin Earth thought experiment. Imagine that in remote place in the galaxy there is a planet where everything is the same as Earth except that, instead of water, it contains a substance exactly similar to but chemically different from water. We may call this substance twater, which is composed of XYZ, as opposed to $\mathrm{H}_{2} \mathrm{O}$. When a normal inhabitant of Earth utters a sentence containing the word 'water,' she thereby expresses a thought about $\mathrm{H}_{2} \mathrm{O}$. For instance, when she says, 'Water is wet,' she naturally expresses a thought whose content is that water is wet. Therefore, her utterance would be true if and only if $\mathrm{H}_{2} \mathrm{O}$ is wet. On the other hand, if her Twin Earth counterpart utters the same sentence, she would express a thought whose content is that twater is wet. This utterance would be true if and only if XYZ is wet. Given that the inner states of the two persons are exactly the same when they utter the sentence, it follows that the mental contents of their intentional states are not solely determined by the intrinsic properties of their cognitive mechanism.

Although content externalism has recently gained popularity, many philosophers have worried about a skeptical view which asserts that the doctrine of content externalism is incompatible with a natural assumption about self-knowledge: that we can know a priori (or "from the armchair") the contents of our own thoughts without investigating our environment pertinent to them. One version of this skepticism is established by relating knowledge to some type of discriminatory ability. With some stipulation, the earthian of the aforementioned Twin Earth case does not seem to be able to discriminate a priori her occurrent thought content (that water is wet) from the alternative thought content (that twater is wet). Provided that knowledge requires some type of discriminatory ability, the skeptic may argue that she does not know a priori her occurrent thought content. The reasoning behind the skepticism can be represented by an argument as follows: 
(DA1) If content externalism is true, we cannot discriminate a priori our occurrent thought content from any relevant alternative thought content.

(DA2) If we cannot discriminate a priori our occurrent thought content from any relevant alternative thought content, then we do not know a priori our occurrent thought content.

Conclusion. If content externalism is true, we do not know a priori our occurrent thought content.

Let us call this the discrimination argument. Many philosophers have argued against it to establish the compatibility of content externalism and self-knowledge. ${ }^{1}$ The strategies of compatibilists tend to move in two directions: either they show that content externalism, despite the worries stemming from the discrimination argument, does not fail the discriminatory ability, or they show that knowledge does not require an ability to discriminate the occurrent thought content and any alternative content. ${ }^{2}$ Quite a number of compatibilists take the former direction, as it seems pressing that knowledge requires some type of discriminatory ability. A classic example that illustrates the discriminability requirement is given by Alvin Goldman (1976, 772-73). Henry is driving in an area which has many barns and papier-mâché facsimiles looking just like barns. Without knowing that some of them are facsimiles, he points to an object, which happens to be a real barn, and says, "That's a barn." Although he correctly identifies the object, he does not seem to know that it is a barn. The most natural explanation for his failure of knowledge is that he could not tell the object at hand from other fake barns, and thus would still believe that he was seeing a real barn even if the target object were a fake barn. This example suggests that an ability to discriminate an external object from other alternative objects is required for perceptual knowledge. Though this example purports to establish the discriminability requirement for perceptual knowledge,

1 For some influential works on this issue, see (Bar-on 2004; Boghossian 1989; Brown 2004; Brueckner 1990; Burge 1988; Falvey and Owens 1994; McKinsey 1991; McLaughlin and Tye 1998; Parent 2017).

2 Here the first and the second strategies amount to rejecting the first and the second premises of the discrimination argument, respectively. 
some people might argue that the same applies to knowledge of our thought contents. Those compatibilists who accept this view are bound to endorse (DA2), while remaining opposed to (DA1).

This type of strategy often appeals to the notion of relevance. According to this strategy, if content externalism is granted, we can discriminate a priori our occurrent thought from other alternative thoughts, as long as the alternatives are relevant. Thus, earthians can normally discriminate a priori the thought that water is wet from the thought that gin is wet or that petroleum is wet, insofar as they live in linguistic environments where the gin- or petroleum-involved thoughts are widely available. Someone may not be able to discriminate his or her thought content that water is wet from the putative alternative content that twater is wet, but for anyone in normal circumstances this alternative content is irrelevant. In other words, unlike Henry's case, the situation where someone is thinking that twater is wet, as described in the beginning of this section, is not a relevant alternative to the situation where a normal earthian is thinking that water is wet.

Many commentators, however, agree that "the slow switch" case provides a scenario where the twater-involved content is a legitimately relevant alternative to a normal water-involved content (Burge 1988, 652-53; Boghossian 1989, 13; Falvey and Owens 1994, 111-12; Brown 2004, 39-40). Imagine that Sally, a fellow earthian, unwittingly traveled to Twin Earth. She resided long enough to replace her old concept of water with the new concept of twater shared by the indigenous inhabitants. ${ }^{3}$ Assuming the truth of content externalism, her utterance 'water is wet' now expresses the content that twater is wet. Suppose she has unwittingly traveled back and forth between the two planets a number of times, and at each stay, she spent sufficient time to switch the concepts involving water or twater.

3 It is widely accepted that the concept someone has retained in one linguistic environment, whether it is the concept of water or of twater, will be replaced by the other if he or she stayed long enough in the other environment and engaged in communicational activities using the concept along with the fellow members of the linguistic community. It may be debatable whether the new concept supersedes or supplements the old concept. But I will not press the issue here. It suffices to say that the water- or twater-related concept he or she retains at each stay would differ from the concept retained in the previous stay of the other environment. 
Under these circumstances, if she resides in earth and forms an occurrent belief that water is wet, then the thought that twater is wet is a relevant alternative, because considering her itinerant history between the two planets, she could have been on Twin Earth thinking that twater is wet. Nevertheless, since Sally is unaware of her trips, she would sincerely believe that the thought she currently has by entertaining the content of "water is wet' is the same as the thought she had by entertaining the content of the same sentence earlier while she was (unwittingly) staying on Twin Earth. Then, Sally seems to lack the ability to discriminate a priori between her occurrent thought that water is wet and a relevant alternative thought that twater is wet. In sum, in the slow switch case, the twater-thought can reasonably be considered a relevant alternative to the water-thought, but the subject is not able to discriminate one from the other. ${ }^{4}$

This type of example is threatening to those who attempt to reject the incompatibility of content externalism and self-knowledge, as specified in (DA1). A number of philosophers have attempted to get round the problem raised by the slow switch case. On the other hand, we may question the truthfulness of the discriminability requirement as specified in (DA2). As we have seen, (DA2) states that knowledge of our thought content requires some type of discriminatory ability. Hence, we can still refute the discrimination argument by showing that we can know a priori our occurrent thought content without being able to discriminate it with relevant alternative contents. Kevin Falvey and Joseph Owens (1994, 109 ff), for example, distinguish what they call introspective knowledge of content, which

4 Peter Ludlow (1995) offers a less fancy example of this sort. There may be actual cases where the denotation of a word can be switched to a similar, albeit distinct, kind of object in a different linguistic community - a kind of object deemed internally identical to the subject. For instance, an international traveler may entertain a thought containing the word 'chicory' in England, and then move to the United States and entertain the corresponding thought that contains the same word, while unaware that the contents of her thoughts in the two occasions differ from each other. This view is sometimes referred to as social externalism. Though I do not discuss the slow switching cases involving social externalism in this paper, my argument here can faithfully be applied to the skepticism of self-knowledge stemming from social externalism as well. For a criticism of social externalism, see (Pollock 2015). 
involves whether you can epistemically access your occurrent thought contents directly and authoritatively, from what they call introspective knowledge of comparative content, which involves whether or not you can tell the difference between any pair of your occurrent thought contents directly and authoritatively. According to their argument, the slow switch case cannot be tenably applied to the former kind of self-knowledge. ${ }^{5}$ In this paper, I aim to offer a novel explanation for why the sort of discriminatory ability that concerns content externalism is not required to establish selfknowledge of our occurrent thought content when focusing on a particular type of using demonstratives. My argument depends on the notion that we cannot possibly misidentify a target object when we refer to it with a demonstrative expression without attributing any particular identificatory property to it. I first build up an argument for a version of the discrimination argument that appeals to a principle of thought individuation suggested by Gareth Evans. Then, I contend that the distinctive feature in the aforementioned use of demonstratives undermines this argument, which reveals the untenability of the discriminability requirement. Finally, I respond to a possible objection to my argument, which claims that even demonstrative denotation allows room for misidentification.

\section{An argument for the discriminability requirement}

Bertrand Russell famously distinguished knowledge by acquaintance from knowledge by description. As a classical foundationalist, Russell held that knowing a proposition must eventually depend on acquaintance with the relevant particulars. In defense of this view, he said that "it is scarcely conceivable that we can make a judgement or entertain a supposition without knowing what it is that we are judging or supposing about" (Russell $1912,58)$. Evans gives an interesting interpretation of this remark to establish a substantial principle about individuating thoughts. While dubbing it Russell's Principle, Evans understands this remark as stating that thinking

5 For a different approach that rejects the discriminability requirement, see (Goldberg 2005 and 2006). 
about an object requires us to possess the ability to discriminate it from anything else. He writes:

In order to make Russell's Principle a substantial principle, I shall suppose that the knowledge which it requires is what might be called discriminating knowledge: the subject must have a capacity to distinguish the object of his judgment from all other things. (Evans 1982, 90)

It may be debatable whether Evans correctly interprets Russell's view here. Nevertheless, Evans seems to impose a quite sensible requirement for the individuation of singular thoughts. We can encapsulate the requirement as follows:

(E) If $S$ is thinking (or making a judgment) about $x$, then $S$ can discriminate $x$ from any object other than $x$.

With regard to (E) and the discrimination argument, compatibilists might hope that, by satisfying (E), we may be able to discriminate a priori between the actual scenario where we have an occurrent thought, and relevant alternative scenarios where we are thinking alternative thoughts, including the Twin Earth analogue of the actual occurrent thought. (E) states that the discriminatory ability is a necessary condition for a subject to think about an object $x$. Let the content of the actual occurrent thought be represented by the form: $x$ is $F$. Given the truth of (E), if we think $x$ is $F$, then we must have the discriminatory ability between $x$ and any other object, including an exact duplicate of $x$ (call it $y$ ). Then, it may be suggested that if (E) is true, then by thinking that $x$ is $F$, we must be able to discriminate a priori between the actual scenario where we are thinking that $x$ is $F$ and any other scenarios where we would be thinking different thoughts, including an alternative scenario where we are thinking that $y$ is $F$.

However, this view is vulnerable to a counterexample. Suppose I am witnessing a seemingly supernatural phenomenon featuring a UFO. A saucer-shaped aircraft appears in the sky, flies in irregular patterns, and then quickly disappears from my sight. Suppose also that, unbeknownst to me, there is another flying object in the vicinity qualitatively identical to the saucer that I witnessed. Let us call the two aircrafts $\mathrm{U}_{1}$ and $\mathrm{U}_{2}$ : $\mathrm{U}_{1}$ is the one that $\mathrm{I}$ witnessed and $\mathrm{U}_{2}$ is the one in the vicinity. At $t_{1}$, while looking 
at $\mathrm{U}_{1}$, I think to myself, 'That moves fast.' Then, without my noticing, $\mathrm{U}_{1}$ is switched to $\mathrm{U}_{2}$. After a while (at $t_{2}$ ), upon looking at $\mathrm{U}_{2}$, I think, 'That moves fast,' taking myself to be thinking about the same object. At this point, I seem to satisfy (E) both at $t_{1}$ and at $t_{2}$. At $t_{1}$ I stand in a certain perceptual relation to $U_{1}$, by virtue of which I visually identify $U_{1}$ and place it at a certain location. Thus, I successfully refer to $\mathrm{U}_{1}$ within my representational system, where no other relevant alternative objects, including $\mathrm{U}_{2}$, exist in that system at $t_{1}$. So, I am thinking about $\mathrm{U}_{1}$ at $t_{1}$, and not about anything else. In the same way, at $t_{2} \mathrm{I}$ visually identify $\mathrm{U}_{2}$ and place it at a certain location. So, I successfully refer to $\mathrm{U}_{2}$ within my representational system, which does not contain any other relevant alternative objects, including $\mathrm{U}_{1}$ at that time. Hence, it is true for me that I am thinking about $\mathrm{U}_{2}$ at $t_{2}$ and not about anything else. However, by stipulation of my thought experiment, I am unable to distinguish between $\mathrm{U}_{1}$ and $\mathrm{U}_{2}$. In particular, I cannot discriminate a priori between the content of the thought I had at $t_{1}$ that that $\left(\mathrm{U}_{1}\right)$ moves fast and the content of the thought $\mathrm{I}$ had at $t_{2}$ that that $\left(\mathrm{U}_{2}\right)$ moves fast. ${ }^{6}$ On being asked, I would sincerely answer that I was thinking the same proposition on both occasions. Thus, this case illustrates that we can distinguish the object of our occurrent thought from any other object, while remaining unable to discriminate the content of our occurrent thought from any relevant alternative contents. In particular, we can think a perceptual demonstrative thought about an object $x$ ('That $(x)$ is $F$ "), while remaining unable to distinguish it from a relevant alternative thought about $y$ ('That $(y)$ is $F^{\prime}$ ), where $x \neq y$.

${ }_{6}$ Here I follow Jessica Brown (2004, 86-89), except that Brown mentions that the subject would not be able to discriminate between her current situation where she thinks a perceptual demonstrative thought and a relevant alternative situation where she thinks the twin analogue of the demonstrative thought (Brown 2004, 89). This is clearly mistaken: in general, people can distinguish their current experiences from phenomenologically identical experiences occurring at different times. To rectify the mistake, here I refer to the discriminatory ability between two tokens of thoughts, as opposed to two different situations, occurring at different times: I am unable to distinguish between my thought that that $\left(\mathrm{U}_{1}\right)$ moves fast, occurring at a certain time, and the relevant alternative thought I am thinking that that $\left(\mathrm{U}_{2}\right)$ moves fast, occurring at a later time. 
The preceding observation reveals that satisfying Evans's requirement for thinking about an object-namely, securing an ability to discriminate between the currently perceived object and any other object - does not entail the ability to discriminate between occurrent thought content and other relevant alternative contents. Hence, compatibilists would not be successful in using (E) to cope with the discrimination argument. Nevertheless, they may claim that (E) can be revised to secure the basis for a special kind of self-knowledge.

To demonstrate this point, let us note that (E) concerns our thought about an object: it aims to show that thinking of a particular object requires an ability to distinguish it from any other object. Compatibilists may argue that thinking of our own thought contents, as opposed to thinking of external objects, gives rise to an interesting result. Tyler Burge (1988) famously argues that what he calls basic self-knowledge is self-verifying. According to him, basic self-knowledge consists of judgments of the following form: $S$ judges that $S$ is thinking that $p$. Burge goes on to claim that, when a person thinks (or judges) that she is thinking that $p$, she is thereby entertaining the thought content that $p$. Entertaining (the content) that $p$ is a type of thinking that $p$. Thus, by judging that she is thinking that $p$, she is indeed thinking that $p$. In other words, when we think:

(*) I am thinking that $p$,

by entertaining the content $(*)$, we thereby make $\left(^{*}\right)$ true. Thus, when we make a judgment about our thinking a particular content, our judgment is self-verifying.

On the Burgean approach, this type of first-person introspective judgment is applicable to the aforementioned slow switch case. Suppose Sally, while on Earth, makes this type of first-person judgment when she thinks that water is wet. Then, we would report her thought by saying that she judges that she is thinking that water is wet. In expressing this judgment, she entertains the thought that water is wet, and thereby is thinking that water is wet. She cannot falsely believe, for example, that she is thinking that twater is wet. The same point applies to the case where Sally is on Twin Earth. When she thinks, 'I am thinking that water is wet,' she makes the judgment that she is thinking that twater is wet. In making this 
judgment, she entertains the thought that twater is wet, and thereby is thinking that twater is wet. Her current aquatic environments render it the case that she cannot falsely be engaged in the water-thought. This shows that Sally cannot be mistaken about her cogito thoughts.

Can the Burgean approach to the self-verifying nature of basic selfknowledge shed light on the compatibility of content externalism and selfknowledge? In my view, the skeptic may use Evans's requirement to argue that the discrimination argument still stands with respect to second-order first-person judgments of our own thought contents. (E) states that thinking of an object requires some type of discriminability. Likewise, the skeptic may suggest that thinking a second-order judgment regarding our own thought from the first-person perspective requires the ability to discriminate between our occurrent thought content and relevant alternative contents, including the twin analogue of the occurrent thought. We can articulate this proposition as follows:

$\left(\mathrm{E}^{\prime}\right) \quad$ If $S$ thinks that $S$ is thinking that $p$, then $S$ can discriminate a priori between $S$ 's occurrent thought that $S$ is thinking that $p$ and any relevant alternative thought that $S$ is thinking that $q($ where $p \neq q)$.

Apart from this, we can naturally assume that knowledge of a particular proposition entails thinking about its content. Hence, it is reasonable to accept the following principle.

(K) If $S$ knows a priori that $S$ is thinking that $p$, then $S$ thinks that $S$ is thinking that $p .^{7}$

Applying simple rules of propositional logic to $(\mathrm{K})$ and $\left(\mathrm{E}^{\prime}\right)$, we can derive:

$\left(\mathrm{DA}^{\prime}\right)$ If $S$ cannot discriminate a priori between $S$ 's occurrent thought that $S$ is thinking that $p$ and any relevant alternative thought that $S$ is thinking that $q$ (where $p \neq q$ ), then $S$ does not know a priori that $S$ is thinking that $p$.

7 Here I intend that $(\mathrm{K})$ is restricted to our occurrent thought. Surely, when I know that a particular proposition is true, I need not concurrently entertain its content. 
This principle states that knowledge also requires discriminatory ability in terms of second-order judgments of our own thought contents. The initial slow switch case is put forward to illustrate that content externalism is incompatible with securing due discriminability in terms of ordinary firstorder judgments about an object. The skeptic might argue that the same is true of introspective second-order judgments about our own thought contents. In the aforementioned slow switch case where Sally judges that she is thinking that water/twater is wet, we noted that we would report her judgment differently depending on whether she makes the judgment on Earth or on Twin Earth. Hence, the two tokens of the introspective secondorder judgments are distinct from each other. However, by the stipulation of the story, Sally would not be able to tell the difference. If asked about the identity of the two judgment tokens, she would sincerely answer that she made exactly the same judgment both times (or so we can stipulate the story). Sally lacks the discriminatory ability as to the introspective secondorder judgments about her own thought contents. We can recapitulate this point as follows:

$\left(\mathrm{DA}^{\prime}\right)$ If content externalism is true, then $S$ cannot discriminate a priori between $S$ 's occurrent thought that $S$ is thinking that $p$ and any relevant alternative thought that $S$ is thinking that $q($ where $p \neq q)$.

From $\left(\mathrm{DA} 1^{\prime}\right)$ and $\left(\mathrm{DA} 2^{\prime}\right)$, we can easily draw the conclusion about the incompatibility of content externalism and self-knowledge involving the second-order judgments of our own thought contents.

This may sound unfavorable for compatibilists. Quite the contrary, however, I think that the preceding observation opens a possibility for them to reject the discrimination argument. Let us first note that $\left(\mathrm{DA} 2^{\prime}\right)$ is an instance of (DA2): while (DA2) concerns the discriminatory ability involving any type of thought, (DA2') concerns the discriminatory ability on a special type of thoughts - namely, the ability to discriminate among second-order judgments concerning our own thought contents. It means that the soundness of the discrimination argument as suggested in the beginning of this paper entails the soundness of this particular version of the argument. Then, since (DA2) entails (DA2'), compatibilists can reject (DA2) by successfully 
refuting (DA2'), and if (DA2) is rejected, then the discrimination argument collapses.

Compatibilists may refute (DA2') by disproving either $\left(\mathrm{E}^{\prime}\right)$ or $(\mathrm{K})$. $(\mathrm{K})$ seems indisputable. However, I think that $\left(\mathrm{E}^{\prime}\right)$ can be disproven. In what follows, I argue that a standard case where we have a second-order judgment regarding our own perceptual demonstrative thought and in which we do not attribute any identificatory property to the referent, constitutes a counterexample to $\left(\mathrm{E}^{\prime}\right)$. In addition, I argue that this sort of case, due to a characteristic feature of this use of demonstrative thoughts, can be used to show that $\left(\mathrm{DA} 2^{\prime}\right)$ is vulnerable to counterexamples as well.

\section{Demonstrative thoughts and the discrimination argument}

As the first step, I would like to note a distinctive feature of demonstrative thoughts. In thinking a demonstrative thought, we do not necessarily take the object at hand as some particular thing. For instance, when I look at a peach in a fruit store and think, 'That looks delicious,' my use of the demonstrative may denote the peach without attributing any identificatory property to it. I may unwittingly have seen the peach before, and I might even have thought that it looked unpalatable at that time. However, as long as I do not remember these facts, I am taking it as some peach or other in my occurrent thought. When we demonstratively denote a perceived object without taking it as some particular thing, I would like to call it the indefinite use of a demonstrative expression. In employing the indefinite use of demonstratives, we are guaranteed to correctly refer to the intended object. For instance, when I see a tree and think, 'That is an elm,' I cannot possibly be mistaken because of misidentification. Of course, I may be erroneous because I falsely ascribe a certain property to the object - e.g., the tree may be a beech. However, in that case, the reason why $\mathrm{I}$ am mistaken is not because I misidentify the object. My use of the demonstrative correctly picks out the intended object. It is just that the correctly identified object lacks the property I ascribe to it. In general, when we indefinitely use a demonstrative to denote a perceived 
object, we are bound to be free of error in identifying the object at hand. ${ }^{8}$

The indefinite use of demonstratives contrasts with the definite use. In employing the definite use, we take the object as some particular thing. This usage allows us to misidentify the object. Suppose I am watching races in a track meet in which my daughter participated. From a distance, I see that a girl, who dresses like my daughter, wins a race. Thinking that she is my daughter, I may proudly shout to the person next to me, "That's my girl!" Here, I am taking the girl as a particular person (namely, my daughter), and thus, there is a sense in which I may be mistaken in identifying the object I intend to identify. ${ }^{9}$ However, insofar as we engage in the indefinite use of a demonstrative and do not take the object as anything (or anyone) in particular, there is no room for us to be mistaken in referring to the intended object. ${ }^{10}$

My contention is that a typical case where we are engaged in the indefinite use of a demonstrative amounts to a counterexample to ( $\left.\mathrm{E}^{\prime}\right)$ and to

8 I do not mean to suggest that, in employing the indefinite use of a demonstrative expression, we can never be mistaken in presuming that the referent in fact exists. We can surely demonstratively refer to a hologram projection of a car, falsely believing that we are seeing a real car. I only want to claim that, in referring to an object with the indefinite use, what we intend to refer to must be identical to what we actually refer to.

$9 \quad$ Even in this case, there are two senses as to how we intend to identify an object. See my discussion of two different interpretations of intended objects in the next section.

10 It may be doubted whether the indefinite use of a demonstrative is possible, given that demonstratives are context-dependent. For instance, drawing upon the Kaplanian approach to indexicals, someone might claim that the same demonstrative expression uttered in different contexts may convey different contents, though have the same character; but a demonstrative should always be definite in a given context. However, in my usage of the term, whether a demonstrative expression is used indefinitely or definitely depends on the epistemic attitude of the subject; and it is surely possible for us to demonstratively refer to an object, and not anything else, in a given context, while at the same time not regarding the object as anything in particular. Therefore, my understanding of the indefinite use of a demonstrative is compatible with the Kaplanian picture. I thank Jihee Han for helping me clarify this point. See (Kaplan 1989) for the details of the Kaplanian view of indexicals. 
$\left(\mathrm{DA} 2^{\prime}\right)$ altogether. To illustrate this point, consider a variation of the aforementioned UFO example. There are two aircrafts, $\mathrm{U}_{1}$ and $\mathrm{U}_{2}$, in the vicinity of the sky I am observing. But this time I do not observe one craft after the other. I only watch $\mathrm{U}_{1}$ and think, 'That moves fast.' Though I did not see $\mathrm{U}_{2}$, under the circumstances, $\mathrm{U}_{2}$ could have been in the place of $\mathrm{U}_{1}$ at the exact moment when I witness $\mathrm{U}_{1}$, and could have flied and disappeared exactly the way $\mathrm{U}_{1}$ did. If that had happened, let us suppose, I would have thought to myself, 'That moves fast.' So, there are two tokens of demonstrative thoughts expressed by the sentence, one actual and the other counterfactual. Let us call the actual and the counterfactual thought contents $p$ and $q$, respectively. According to content externalism, $p$ and $q$ are tokens of two different thoughts, since $p$ stands for a thought about $\mathrm{U}_{1}$ while $q$ stands for a thought about $\mathrm{U}_{2}$. Now, suppose that while looking at $\mathrm{U}_{1}$, I introspectively make a judgment, 'I am thinking that that moves fast.' Then, we would report my second-order judgment by saying that I think that I am thinking that $p$. Let us stipulate that if I had witnessed $\mathrm{U}_{2}$ instead, I would have formed the corresponding second-order introspective judgment involving $q$. This counterfactual second-order judgment is a relevant alternative to the actual second-order judgment involving $p$, given that I could have witnessed $\mathrm{U}_{2}$ instead of $\mathrm{U}_{1}$, and thus that I could have had the thought with the content $q$ instead of the thought with the content $p$.

Nevertheless, it is natural to assume that I cannot discriminate a priori the contents of the two second-order introspective judgments. Compare the above-mentioned UFO example with the original version of the story where I witness the movements of the two aircrafts one after the other, mistakenly believing that they are one and the same. In the original version, imagine that, at each of my observations, I make the second-order introspective judgment, 'I am thinking that that moves fast.' Since I did not know that the aircrafts are not identical, I would think that I made the same judgment twice (or so we could stipulate the story). If I am asked, I would sincerely report that the content of the judgment I made at each time was exactly the same. Here, the actual situation where I make the second-order introspective judgment featuring $\mathrm{U}_{2}$ does not significantly differ from the counterfactual situation where I make the same second-order judgment involving $q$ in the above-mentioned variation of the story. Therefore, we could 
reasonably infer that, in the above-mentioned variation of the story as well, I would not be able to tell the difference between my actual second-order judgment involving $p$ and the counterfactual second-order judgment involving $q$. Still, when I make the second-order introspective judgment in the actual situation, the content of my judgment involves $p$, and not $q$, since I make this judgment while looking at $\mathrm{U}_{1}$. Thus, it is clear that, in the actual situation, I think that I am thinking that $p$, as opposed to thinking that I am thinking that $q$. This shows that $\left(\mathrm{E}^{\prime}\right)$ is vulnerable to a counterexample.

The preceding observation shows that I can think a second-order introspective thought with a demonstrative content without necessarily being able to discriminate it from any relevant alternative thought with a different demonstrative content. This is in part because I indefinitely used the demonstrative expression in denoting the perceived object. When I think, 'I am thinking that that moves fast,' my use of the demonstrative expression enables me to refer to the object without attaching any identificatory characteristics to it. Due to this feature, I am guaranteed to be successful in referring to the object that I am in fact referring to. That is, my thought is guaranteed to be about my first-order thought with the $\mathrm{U}_{1}$ content as opposed to, say, the $\mathrm{U}_{2}$ content (or any other content, for that matter). I need not be able to distinguish the thought with the $\mathrm{U}_{1}$ content from any relevant alternative thought such as one with the $\mathrm{U}_{2}$ content, because when I refer to $\mathrm{U}_{1}$ with the indefinite use of the demonstrative, the truth condition of my utterance does not require that I successfully refer to $U_{1}$.

Furthermore, I want to claim that, in the above-mentioned variation of the UFO story, I can be said to know the content of my thought without having the ability to discriminate between the two introspective thoughts. Since I had never seen the UFO I witnessed in this incident before, when I think, 'I am thinking that that moves fast,' I would not take "that" as anything in particular. I would only take it to be some thing or other, just as I would take the peach as some peach or other in the fruit store. When I introspectively think, 'I am thinking that that moves fast,' I make a judgment that I am thinking that that $\left(\mathrm{U}_{1}\right)$ moves fast-i.e., I make a judgment that I am thinking that $p$. Following the Burgean approach, this judgment is self-verifying because, in making it, I entertain the thought that $p$, and 
thus am thinking that $p$. I cannot falsely believe, for example, that I am thinking that $q$, because, given that I never encountered $\mathrm{U}_{2}$ before, and thus would not take the flying object I am currently watching as any particular thing, there is no ground for me to think that the content of my thought concerns $\mathrm{U}_{2}$. I cannot misidentify the object in the content of my thought as something else simply because I do not attribute any identificatory property to the object I am witnessing. We can articulate this observation as follows:

(D) Insofar as $S$ refers to $x$ with the indefinite use of a demonstrative expression, $S$ s judgment that $S$ is thinking that $x$ is $F$ is selfverifying.

Now, suppose I am a devoted epistemologist, and (D) is the conclusion I reached as a result of my academic research on how demonstratives work. For this reason, let us stipulate, I was ready to resort to (D) when I witnessed the UFO incident. If (D) is correct, then when I see the aircraft and think, 'I am thinking that that moves fast,' I judge that I am thinking that that $\left(\mathrm{U}_{1}\right)$ moves fast - i.e., I judge that I am thinking that $p$. This judgment is true and self-verifying, and by virtue of knowing (D), I am entitled to know the truth and the self-verifiability of my judgment. Thus, I can justifiably claim that I know that I am thinking that $p$, although I admittedly cannot discriminate a priori between my actual occurrent thought with the content $p$ and a thought with a relevant alternative content such as $q$. Thus, the UFO story constitutes a counterexample to (DA2').

Here my knowledge about the content of my occurrent thought partly depends on my understanding of how the demonstrative works in the statement expressing my thought. Since I am aware of (D), in judging that I am thinking that that moves fast, I know that what I am thinking is about whatever is designated by my indefinite use of the demonstrative expression. I also know that in using the demonstrative, I do not attribute any identificatory property to the referent. For this reason, I know that I cannot be mistaken in designating the referent with my use of the demonstrative expression. Consequently, I am entitled to know that the content of my thought is the very proposition containing the demonstrative, as opposed to an alternative proposition whose content is indistinguishable to me. In 
other words, when I know (D), if I judge that I am thinking that $p$, then I know what I am thinking is the content $p$, as opposed to the content $q$, where $p$ and $q$ are distinct but nonetheless indistinguishable contents to me. This line of reasoning can be suitably extended to accommodate the skeptical view about content externalism involving the slow switch example. Suppose, in the aforementioned slow switch case, Sally is a prominent Burgean scholar who is well aware of the self-verifying nature of basic selfknowledge. She would know that she cannot possibly misidentify the referent of 'water' in uttering the word, whether her current aquatic environments involve water-thoughts or twater-thoughts. Then, when she thinks, 'I am thinking that water is wet,' she knows that she cannot be mistaken about the content of her first-order thought. This is because she knows that there is no possible way she could mistakenly judge that she is thinking that water is wet, when she in fact judges that she is thinking that twater is wet in the twater-environments. Likewise, she knows that there is no possible way she could falsely judge that she is thinking that twater is wet when she in fact judges that she is thinking that water is wet in the water-environments. However, she cannot ex hypothesi discriminate between the water-thoughts and the corresponding twater-thoughts. Once again, (DA2') is falsified. ${ }^{11}$

This completes my argument against the discrimination argument. I now turn to a possible objection to the key idea of my argument, and attempt to defend my argument against it.

\section{Demonstrative thoughts and immunity of error through misidentification}

The core of my argument lies in the proposition that while thinking a thought where we demonstratively refer to an object without attributing any identificatory property to it, we cannot possibly misidentify it. ${ }^{12}$ Along

11 I am grateful to an anonymous reviewer for Organon $F$ for pressing me to clarify the discussion in this paragraph.

12 In particular, my argument involves the impossibility of misidentification in second-order demonstrative thoughts. However, here the impossibility of misidentification ultimately resorts to the impossibility of misidentification in a typical case of 
this line of thought, in the preceding UFO example, when I look at the unidentified aircraft and think, 'That moves fast,' there is simply no room for me to misidentify the object, given that I do not take the aircraft as some particular object. ${ }^{13}$ To use philosophical jargon, my thought (or judgment) may be said to be "immune to error through misidentification" (IETM, henceforth).

To reject my argument, defenders of the discrimination argument may argue that judgments that demonstratively denote an object are not necessarily IETM. The following example by Sydney Shoemaker may illuminate their purpose.

Suppose that I am selling neckties, that a customer wants a red necktie, and that I believe I have put a particular red silk necktie on a shelf of the showcase that is visible to the customer but not to me. Putting my hand on a necktie on that shelf, and feeling it to be silk, I might say "This one is red." (Shoemaker 1968, 558)

Shoemaker points out that, in this case, there is a disparity between the intended reference and the actual reference. When the subject utters, "This one is red," he intends to refer to the necktie he believes he put on the shelf earlier, while it is possible that the intended object is not identical to the object he is in fact referring to. So, he can sensibly ask himself, 'There is some red silk necktie on the shelf, but is it this one?' In other words, in making the utterance "This one is red," he can possibly make the following inference: " $x=$ the necktie that I put on the shelf; the necktie that I put on the shelf was red; thus, $x$ is red." It might be argued that the fact that this sort of inference is possible indicates the disparity. According to this objection, since this inference clearly involves the identification of the intended reference and the actual reference, surely there is room for misidentification. Consequently, the subject's utterance is not IETM.

the indefinite use of first-order demonstrative thoughts. For this reason, in this section I will only discuss more plain cases of such impossibility that do not involve the second-order thoughts. However, the discussion in this section can faithfully be applied to the corresponding second-order demonstrative thoughts as well.

13 Here, I stipulate that what I am seeing does exist-i.e., I disregard the possibilities that I am daydreaming, hallucinating, and so on. 
I think that compatibilists can give at least two answers in response to this objection. First, they may question whether there really is a disparity between the intended reference and the actual reference in Shoemaker's example. Instead, they can say that there may be two different senses of intended reference. Shoemaker speaks of the disparity because the subject intends to refer to the necktie he believes he put on the shelf earlier, but what he actually refers to may not be that necktie. However, it is also correct to say that in uttering "This one is red," the subject intends to refer to the object he is currently touching, and what he is touching is what he is actually referring to at that moment. Thus, the intention of the subject is doubled in this case: he intends to refer to the necktie which he believes he put on the shelf earlier, but at the same time, he intends to refer to the object with which he is currently in tactual contact. We may call the two senses of his intentions descriptive and non-descriptive intentions. In this example, the subject descriptively intends to refer to the necktie he believes he put on the shelf earlier, in the sense that what he intends to refer to is the object that exactly fits the description at hand (namely, "the necktie he believes he put on the shelf earlier"). On the other hand, he non-descriptively intends to refer to what he is currently touching because in this case it is not by virtue of fitting the description that he successfully refers to the intended object: the description does not play any role in his denoting the referent. Speaking of non-descriptive intentions, there is no disparity between the actual and the intended references in Shoemaker's example, since he wishes to refer to the necktie that he is currently in tactual contact with, and he successfully refers to it.

Note that it is non-descriptive intention that is pertinent to my argument against the discrimination argument. My argument appeals to the indefinite use of demonstratives, where the subject's demonstrative expression denotes the object without recourse to any descriptive characterizations. For instance, in the original UFO story, when I look at the UFO and think that that moves fast, I do not refer to the aircraft by attributing any description to it, such as "the shiny flying saucer with irregular patterns." I simply refer to the visually perceived object as "that." By contrast, the subject of Shoemaker's example takes the intended object as some particular thing: he takes the necktie he is currently touching as the one which he had 
put on the shelf earlier. However, this does not entail that there is room for him to misidentify the object. Suppose it turns out that the necktie he is currently touching is actually not the one he put on the shelf earlier. When the subject utters, "This one is red," he does not intend to refer to the object he believes he put on the shelf earlier no matter what that object is. Rather, he intends to refer to the object with which he is in contact, falsely believing it is the necktie he put on the shelf earlier. Hence, what he is doing is ascribing such-and-such property to the object with which he has a perceptual contact, as opposed to (mis)identifying the object with which he is in contact with the object he characterizes with a certain description. As a result, opponents of my argument are misguided in saying that, in Shoemaker's example, the judgment of the subject is not IETM. His judgment may be erroneous: however, if there is an error in his judgment, it would not be due to misidentification; rather it would be due to misattribution, because in that case he would be attributing a wrong property to the correctly-identified object. ${ }^{14}$ This consideration reveals that Shoemaker's example does no harm to my argument.

Second, even if we grant that not all uses of demonstratives are IETM, certain uses of demonstratives are; and as a canonical case of perceptual demonstrative use, the demonstrative expression used in my argument is IETM. In his discussion on self-reference, Shoemaker $(1968,558)$ compares the case quoted above with a plain case where the subject points to a red necktie he is seeing and says, "This is red." He acknowledges that in the latter, unlike the former, the subject does not identify the object as some particular thing, and thus there is no room for misidentification. Here we may sensibly ask what causes the difference between the two cases. Why is it that the subject's utterance in the latter is IETM while the same utterance in the former is not? In my view, this is because, in making the utterance in the latter, unlike the former, the subject has a perceptual contact

14 Similarly, in the slow switch case, Sally can be mistaken if she thinks on Twin Earth, 'I am thinking that water is composed of $\mathrm{H}_{2} \mathrm{O}$.' However, in that case, the error occurs because she misattributes the property of her thought: it is not due to misidentification. In fact, Sally would need to accurately represent her first-order thought in order to misattribute a property to it at all. I am indebted to an anonymous reviewer for Organon $F$ for this point. 
with the object in the relevant way. This is not to say that the subject in the former is not in any way perceptually in contact with the object, since he is clearly in contact with the object tactually. However, the tactual contact is not pertinent to his judging the object as a red one - it may only be relevant to judging it as a silky one. When making a perceptual judgment, to judge that an object has certain color, the subject is required to have visual contact with the object. Touching the necktie is simply irrelevant to telling its color - though, again, it may be relevant to making a judgment about its texture. In this sense, the subject in the former case fails to have the relevant type of perceptual contact with the object. On the other hand, the subject in the latter case has visual contact with the object, and this perceptual contact is relevant to his judgment of the object as being red. From this observation, I contend that a demonstrative judgment is IETM if the subject is in the relevant type of perceptual contact with the object in making the judgment, even if not all demonstrative judgments are IETM. $^{15}$

Let us now reconsider the UFO example. We can easily note that I am in the right sort of perceptual contact with the aircraft when I make the judgment that that moves fast, given that I make this judgment on the basis of my visual experiences. For instance, I may make this judgment based on how fast it looks. As a standard case where we use a demonstrative to denote a perceptually recognized object, this example is analogous to the case where the subject simply looks at a red necktie and says, "This is red." Hence, in making the judgment about the UFO, my use of the demonstrative expression is IETM, whether or not all demonstrative thoughts are IETM.

15 In fact, we might argue that it is not surprising that not all demonstrative uses are IETM. It is well-known that Ludwig Wittgenstein (1958, 66-67) once distinguished two uses of the term 'I': 'I' as subject use and 'I' as object use. Among them, it is widely accepted that 'I' as subject use is IETM. It may be argued that the uses of demonstrative terms can be divided in a similar way: the ones that involve the judgment of which the subject has the right sort of perceptual contact with the object, and the ones that do not. In my view, the former is IETM while the latter may not. 


\section{Conclusion}

It is widely held that knowledge requires some sort of discriminability. We may call this requirement the discriminability thesis. The discriminability thesis gives rise to the skeptical view that content externalism is incompatible with self-knowledge of our own thought content. This skepticism is embodied by the discrimination argument, which claims that knowledge of our own thought requires the ability to discriminate between our occurrent thought content and any relevant alternative contents. In this paper, I argued that understanding the nature of the indefinite use of a demonstrative helps us to see that the discriminability thesis does not apply to self-knowledge. In my view, when we demonstratively denote an object without taking it as anything in particular, our second-order judgment about our own thinking, whose content includes the indefinite use of a demonstrative, constitutes knowledge without due discriminability, thereby making a case against the discriminability thesis in terms of our own thoughts. I also showed that this approach can be faithfully applied to handle the skeptical view that references the slow switch case. Given the wide acceptance of the discriminability thesis, my argument is worth noting.

\section{Acknowledgments}

I am grateful to an anonymous reviewer for Organon $F$ for giving me helpful comments. I also thank Jihee Han for discussing an earlier version of this paper.

\section{Funding}

This work was supported by the National Research Foundation of Korea (NRF) Grant funded by the Korean Government (MSIP) (No. NRF-2015R1A5A7037825).

\section{References}

Bar-on, Dorit. 2004. "Externalism and Self-Knowledge: Content, Use, and Expression." Noûs 38 (3): 430-55. https://doi.org/10.1111/j.0029-4624.2004.00477.x Boghossian, Paul. 1989. "Content and Self-Knowledge." Philosophical Topics 17 (1): 5-26. https://doi.org/10.5840/philtopics198917110

Brown, Jessica. 2004. Anti-Individualism and Knowledge. Cambridge: MIT Press. 
Brueckner, Anthony. 1990. "Scepticism about Knowledge of Content." Mind 99

(395): 447-51. https://doi.org/10.1093/mind/XCIX.395.446

Burge, Tyler. 1988. "Individualism and Self-Knowledge." Journal of Philosophy 85

(1): 649-63. https://doi.org/10.5840/jphil1988851112

Evans, Gareth. 1982. The Varieties of Reference. Oxford: Oxford University Press.

Falvey, Kevin, and Joseph Owens. 1994. "Externalism, Self-Knowledge, and Skepticism." Philosophical Review 103 (1): 107-37. https://doi.org/10.2307/2185874

Goldberg, Sanford. 2005. "The Dialectical Context of Boghossian's Memory Argument." Canadian Journal of Philosophy 35 (1): 135-48.

https://doi.org/10.1080/00455091.2005.10716584

Goldberg, Sanford. 2006. "Brown on Knowledge and Discriminability." Pacific Philosophical Quarterly 87 (3): 301-14.

Goldman, Alvin. 1976. "Discrimination and Perceptual Knowledge." Journal of Philosophy 73 (20): 771-91. https://doi.org/10.2307/2025679

Kaplan, David. 1989. "Demonstratives." In Themes from Kaplan, edited by J. Almog, J. Perry, and H. Wettstein, 481-563. Oxford: Oxford University Press.

Ludlow, Peter. 1995. "Externalism, Self-Knowledge, and the Prevalence of SlowSwitching." Analysis 55 (1): 45-49. https://doi.org/10.1093/analys/55.1.45

McKinsey, Michael. 1991. "Anti-Individualism and Privileged Access." Analysis 51 (1): 9-16. https://doi.org/10.1093/analys/51.1.9

McLaughlin, Brian P., and Michael Tye. 1998. "Is Content-Externalism Compatible with Privileged Access?" Philosophical Review 107 (3): 349-80. https://doi.org/10.2307/2998442

Parent, Ted. 2017. Self-Reflection for the Opaque Mind. New York: Routledge. Pollock, Joey. 2015. "Social Externalism and the Problem of Communication." Philosophical Studies 172 (12): 3229-51. https://doi.org/10.1007/s11098-0150467-4

Putnam, Hilary. 1975. "Meaning of 'Meaning'." In Mind, Language, and Reality: Philosophical Papers, vol. 2, 215-71. Cambridge: Cambridge University Press.

Russell, Bertrand. 1912. The Problem of Philosophy. Reprinted with the introduction by John Perry, 1997. Oxford: Oxford University Press.

Shoemaker, Sydney. 1968. "Self-Reference and Self-Awareness." Journal of Philosophy 65 (19): 555-67. https://doi.org/10.2307/2024121

Wittgenstein, Ludwig. 1958. The Blue and Brown Books. New York: Oxford. 